\title{
Angiofibroma Celular Retroperitoneal: Uma Entidade Rara na Ginecologia
}

\author{
Retroperitoneal Cellular Angiofibroma: A Rare \\ Gynecological Entity
}

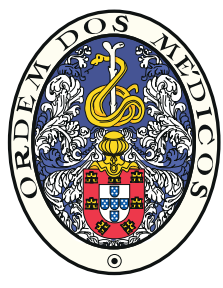

Ana BRANDÃO $\ 1$, Sara CAMPOS ${ }^{1}$, João FRAGA², Teresa SILVA², Fernanda ÁGUAS ${ }^{1}$

Acta Med Port 2017 Dec;30(12):882-886 - https://doi.org/10.20344/amp.8774

\begin{abstract}
RESUMO
O angiofibroma celular é uma entidade tumoral mesenquimatosa rara, descrita pela primeira vez em 1997, sem predomínio de género e que surge tendencialmente na quarta década de vida. A localização mais habitual na mulher é superficial a nível da região vulvovaginal, confundindo-se muitas vezes a nível vulvar com quisto/tumor da glândula de Bartholin. No entanto, estão descritos alguns casos de tumor em localização profunda e extra-pélvica. O tratamento é excisional e a recorrência é baixa. É apresentado um caso de uma paciente com uma formação heterogénea a nível da região anexial direita, cuja cirurgia mostrou tratar-se de uma formação nodular alongada, retroperitoneal, localizada a nível dos espaços paracervical e paravesical direitos, que se excisou. O estudo histológico revelou tumor mesenquimatoso compatível com angiofibroma celular.
\end{abstract}

Palavras-chave: Angiofibroma; Neoplasias Retroperitoneais

\section{ABSTRACT}

Cellular angiofibroma is a mesenchymal tumor, described in 1997, without gender preference, that usually appears at age 40 . The vulvovaginal area is the most common site in women, mimicking vulvar benign tumors, like Bartholin gland cyst. However, there are a few described cases of a deep or extra-pelvic angiofibroma. Excision is the treatment of choice and the recurrence rate appears to be low. We present the case of a woman with a heterogeneous tumor in the right adnexial region. At the surgery, a retroperitoneal tumor was excised and the histopathological tissue analysis revealed a cellular angiofibroma.

Keywords: Angiofibroma; Retroperitoneal Neoplasms

\section{INTRODUÇÃO}

$\mathrm{O}$ angiofibroma celular (AC), descrito pela primeira vez em 1997, é uma entidade rara, com origem no tecido mesenquimatoso, sem predomínio de género e que surge na quarta década de vida. ${ }^{1-4}$ Consiste numa formação tumoral benigna, bem circunscrita, de consistência duro-elástica, com dimensões habitualmente inferiores a $3 \mathrm{~cm} \cdot{ }^{1-5}$

A localização mais habitual na mulher é superficial, a nível da região vulvovaginal. ${ }^{4}$ No entanto, a literatura descreve casos de tumor em localização profunda e extra-pélvica. ${ }^{3,5} \mathrm{Um}$ artigo de revisão da literatura, realizado por Mandato et a ${ }^{\beta}$ em 2015, agrupou 74 casos de AC em mulheres, com uma idade média de 46,1 anos, a maioria de localização superficial, sobretudo a nível vulvar. Dos 74 casos descritos, seis são de localização extrapélvica, com as dimensões médias de $4,38 \mathrm{~cm}$, com apenas um caso de localização pélvica retroperitoneal com crescimento no espaço paravesical direito. ${ }^{3}$

O tratamento descrito para este tipo de lesões consiste na sua excisão local completa, com margens livres. ${ }^{1-3}$ Dos casos descritos com seguimento pós-operatório, verificou-se que o risco de recorrência é baixo, mesmo em lesões com áreas de atipia ou transformação sarcomatosa. ${ }^{1,3}$

As várias hipóteses clinicas de diagnóstico diferencial estão dependentes da sua localização e consistem em quistos da glândula de Bartholin, ${ }^{4}$ outros quistos vulvares, leiomiomas, lipomas e outros tumores sólidos não especi- ficados. ${ }^{3}$ Histologicamente, estas lesões são caraterizadas por três constituintes: células fusiformes que formam pequenos fascículos envolvidos por feixes de colagénio, numerosos e proeminentes vasos sanguíneos, por vezes com parede hialinizada e tecido adiposo por entre as células fusiformes. ${ }^{3,4,6}$ Desta forma, o diagnóstico histológico diferencial é feito com angiomixomas agressivos, angiomiofibroblastoma, lipoma de células fusiformes, tumores fibrosos, perineurinomas e leiomiomas. ${ }^{1,2,4,5}$ Do ponto de vista imunohistoquímico o AC carateriza-se por positividade para vimentina, recetores de estrogénio e progesterona e actina do músculo liso, sendo CD34 positivo em $60 \%$ dos casos. O tumor é negativo para proteína $\$ 100$, desmina e antigénio da membrana epitelial. ${ }^{1,2,4-6} A$ positividade quase sempre observada para receptores de estrogénio e progesterona, sugere uma origem provável no tecido mesenquimatoso subepitelial do tracto genital inferior feminino. ${ }^{7}$

Apesar de serem poucos os casos descritos literatura e com pouco tempo de seguimento, o prognóstico destas lesões parece ser bom, com baixo risco de recorrência. ${ }^{3}$

\section{CASO CLÍNICO}

Doente do sexo feminino, caucasiana, com 44 anos de idade. Dos antecedentes médicos salientamos a sarcoidose e dos antecedentes ginecológicos e obstétricos salientamos os ciclos menstruais regulares, a contraceção com

\footnotetext{
1. Serviço de Ginecologia A. Centro Hospitalar e Universitário de Coimbra. Coimbra. Portugal.

2. Serviço de Anatomia Patológica. Centro Hospitalar e Universitário de Coimbra. Coimbra. Portugal.

$\triangle$ Autor correspondente: Ana Brandão. anam_brandao@hotmail.com

Recebido: 02 de fevereiro de 2017 - Aceite: 31 de maio de 2017 | Copyright @ Ordem dos Médicos 2017
} 

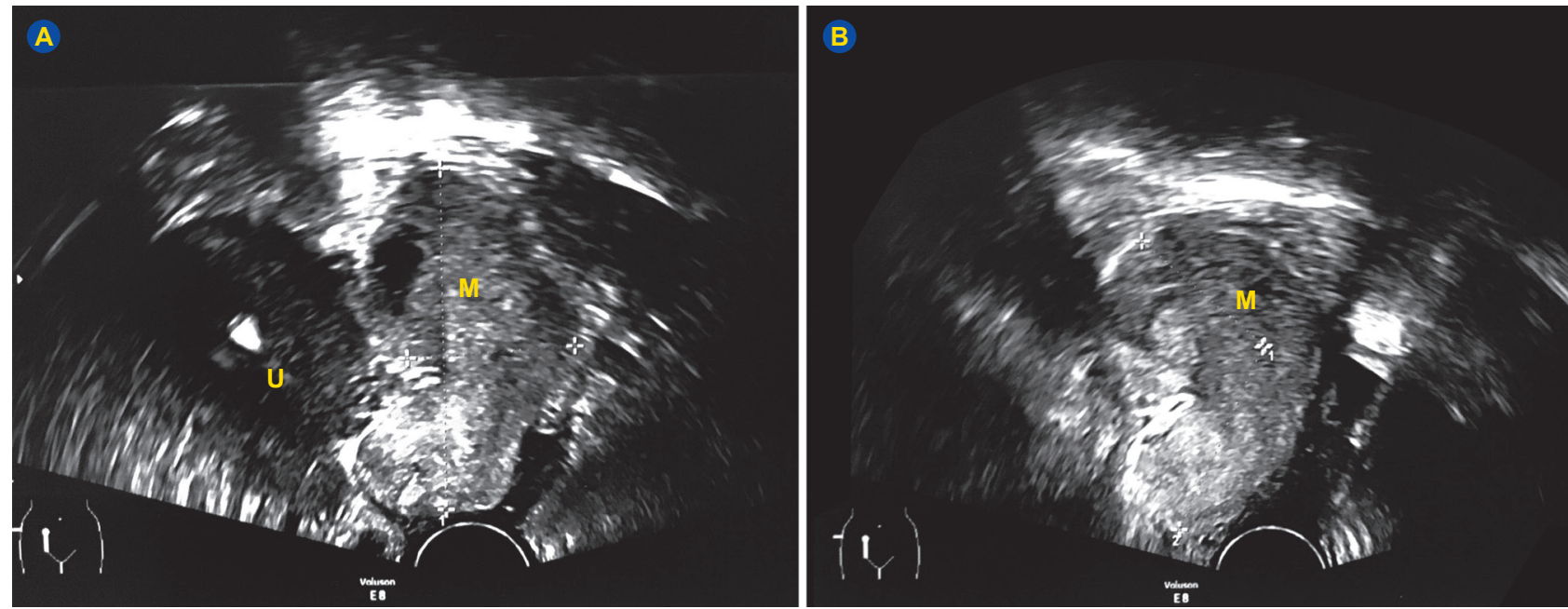

Figura 1 - Ecografia ginecológica transvaginal - formação $(M)$ alongada hipoecogénica com vascularização não suspeita na região anexial direita, longitudinal ao útero $(U)$

dispositivo intrauterino (DIU) de cobre e duas gestações com dois partos eutócicos. Vigilância ginecológica regular, com informação de quisto do ovário direito já conhecido, em vigilância clínica e imagiológica até à data.

Foi enviada ao serviço de Ginecologia com queixas de dor na fossa ilíaca direita com dois meses de evolução, sem alterações do trânsito gastro-intestinal ou urinárias, sem alterações dos ciclos menstruais e sem febre. O exame clínico ginecológico foi normal com toque bimanual indolor à palpação profunda, sem aparentes massas palpáveis.

Dos exames complementares de diagnóstico salientam-se: a ecografia transvaginal (Fig. 1) revelou útero em moderado latero-desvio esquerdo com as dimensões de 80 x 44 x $47 \mathrm{~mm}$ de eixos $\mathrm{L}$ x AP $\times$ T de contornos regulares e normal textura do miométrio. Cavidade endometrial contendo DIU de cobre bem posicionado. Anexos sem ovários identificados e sem derrame líquido pélvico. Na região anexial direita e longitudinalmente ao útero identifica-se uma imagem alongada com 79 × 35 mm hipoecogénica e escassamente vascularizada podendo corresponder a salpinge com aspeto denso; a tomografia computorizada abdomino-pélvica (TC-AP) mostrou em topografia anexial posterior direita, um processo expansivo, hipodenso, discretamente heterogéneo, de contornos regulares, medindo 85 x $47 \mathrm{~mm}$ (Fig. 2). A porção mais inferior encontrava-se adjacente à região ístmica/colo uterino com 60 x 40 mm (Fig. 3).
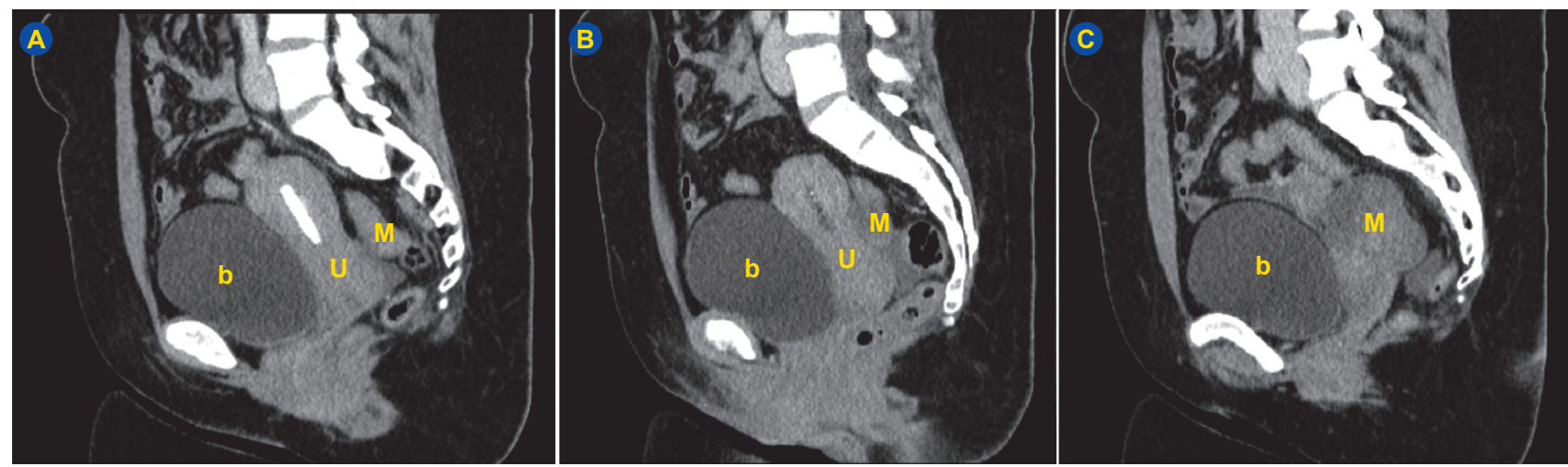

Figura 2 - Imagens seriadas de tomografia computorizada-abdomino pélvica em corte sagital, desde um corte central (A) até um corte mais à direita do útero $(B, C)$ onde se visualiza a massa tumoral $(M)$ e as suas relações anatómicas com a bexiga $(b)$ e útero $(U)$
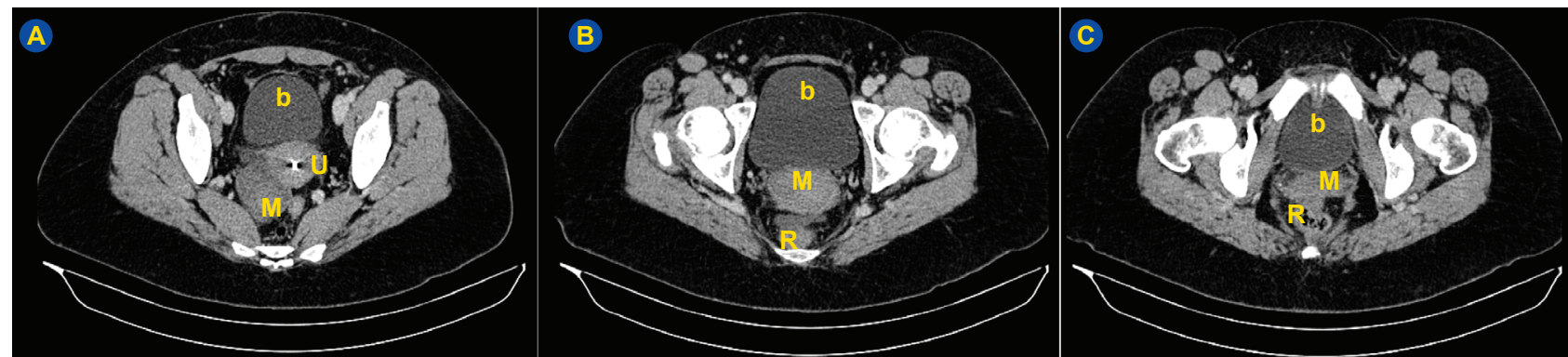

Figura 3 - Imagens seriadas de tomografia computorizada-abdomino pélvica em corte transversal, desde um corte mais apical a nível do istmo $(A)$ até um corte mais caudal $(B$ e $C)$ a nível do recto $(R)$.

b: bexiga; M: massa; U: útero. 


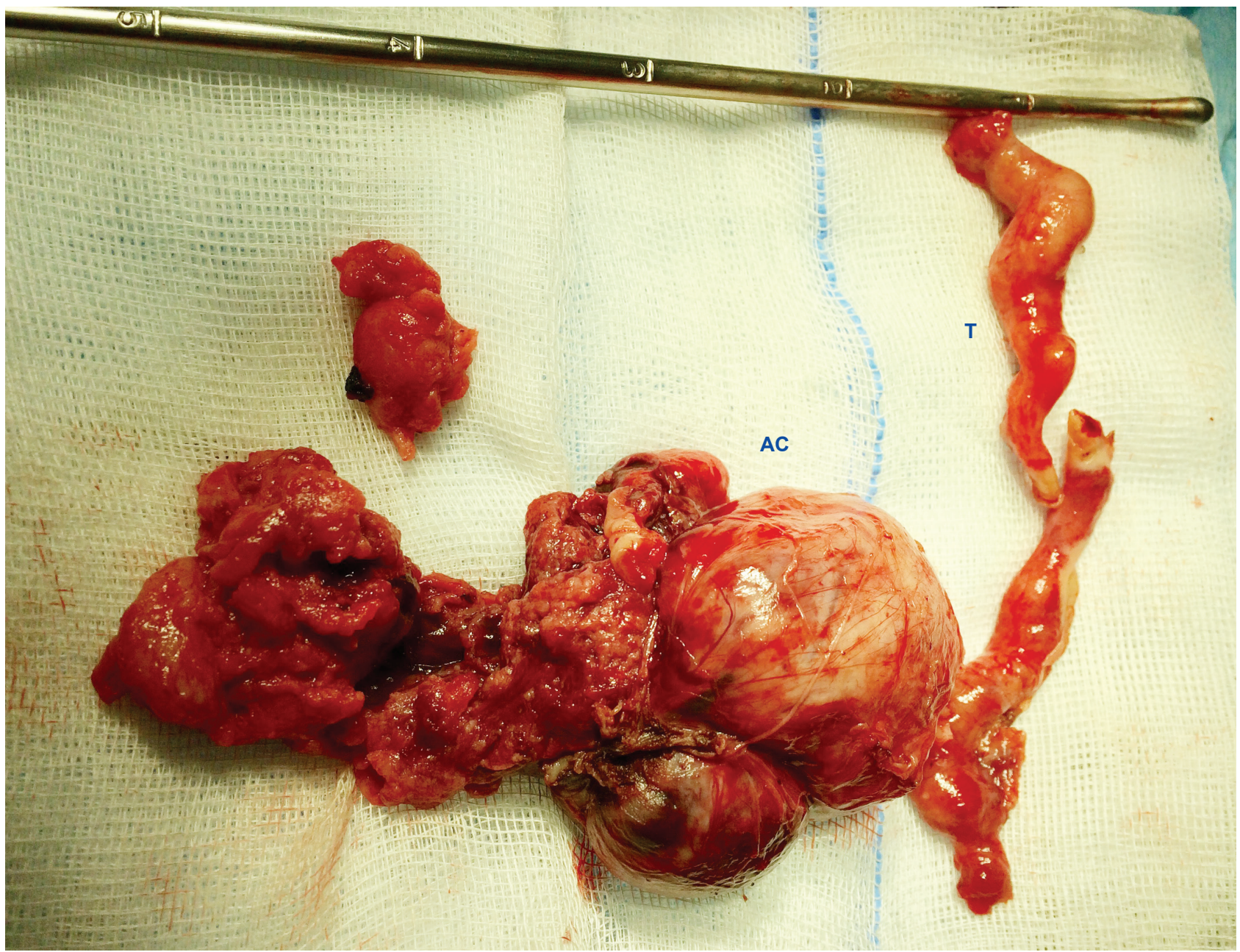

Figura 4 - Imagem da peça operatória após a sua excisão - angiofibroma celular (AC) e trompas (T)

Analiticamente, apresentava o CA 125 de $38 \mathrm{U} / \mathrm{mL}$ (valor de referência de normalidade $<27 \mathrm{U} / \mathrm{mL}$ ) e PCR de 0,12 $\mathrm{mg} / \mathrm{L}$ (valor de referência de normalidade $<0,50 \mathrm{mg} / \mathrm{L}$ ).

Foi submetida a laparoscopia diagnóstica, na qual visualizámos útero e anexos normais e uma formação nodular retroperitoneal em localização laterouterina a nível do paramétrio/paracérvix direito, de consistência duro-elástica que se prolongava na sua profundidade a nível do espaço paravesical direito, pouco vascularizada, não tendo sido identificado a sua origem/dependência. Realizámos salpingectomia profilática bilateral seguida de excisão da formação descrita (Fig. 4). Enviámos a peça operatória para estudo extemporâneo cujo diagnóstico foi diferido para inclusão em parafina, mas não revelou características de malignidade ("lesão constituída por estroma conjuntivo denso fibrosos/hialino, frequentemente de disposição multinodular envolvendo estruturas vasculares, com endotélios sem atípia ou proliferação").

O estudo histopatológico definitivo relevou macroscopicamente uma formação com $7,5 \mathrm{~cm}$ de maior eixo, sobre a extremidade de aspecto nodular com $4,5 \times 4 \mathrm{~cm}$ de superfície externa em parte irregular e em parte lisa, brilhante de aspeto congestivo. Histologicamente observou-se tumor mesenquimatoso sem características de malignidade, com aspectos histomorfológicos e imunofenotípicos que o enquadram num angiofibroma celular. Ausência de imunomarcação para CD34 (que põe em evidência o exuberante componente vascular), para proteína S100, Melan A, CD31, HMB45, C-kit, DOG1, EMA e AE1/AE3. Imunomarcação forte difusa para recetores de estrogénios e recetores de progesterona e também positividade intensa para actina do músculo liso, desmina, $\mathrm{H}$-caldesmon e calponina. A atividade proliferativa avaliada pelo Ki67 é da ordem dos $2 \%$ a $3 \%$ (Fig. 5).

O pós-operatório imediato e tardio decorreu sem incidentes, encontrando-se a doente em consultas anuais de vigilância clínica e imagiológica, com ecografia endovaginal.

\section{DISCUSSÃO}

O angiofibroma celular é um tumor benigno com origem nas células mesenquimatosas e que se apresenta sob a forma de lesões nodulares bem limitadas, de consistência duro-elástica, constituídas por células fusiformes e vasos sanguíneos. ${ }^{1-5}$ Dado que a primeira descrição desta entidade remonta apenas a 1997, são ainda poucos os casos descritos na literatura, limitando assim o conhecimento exato acerca da sua evolução e prognóstico. Contudo, e de 

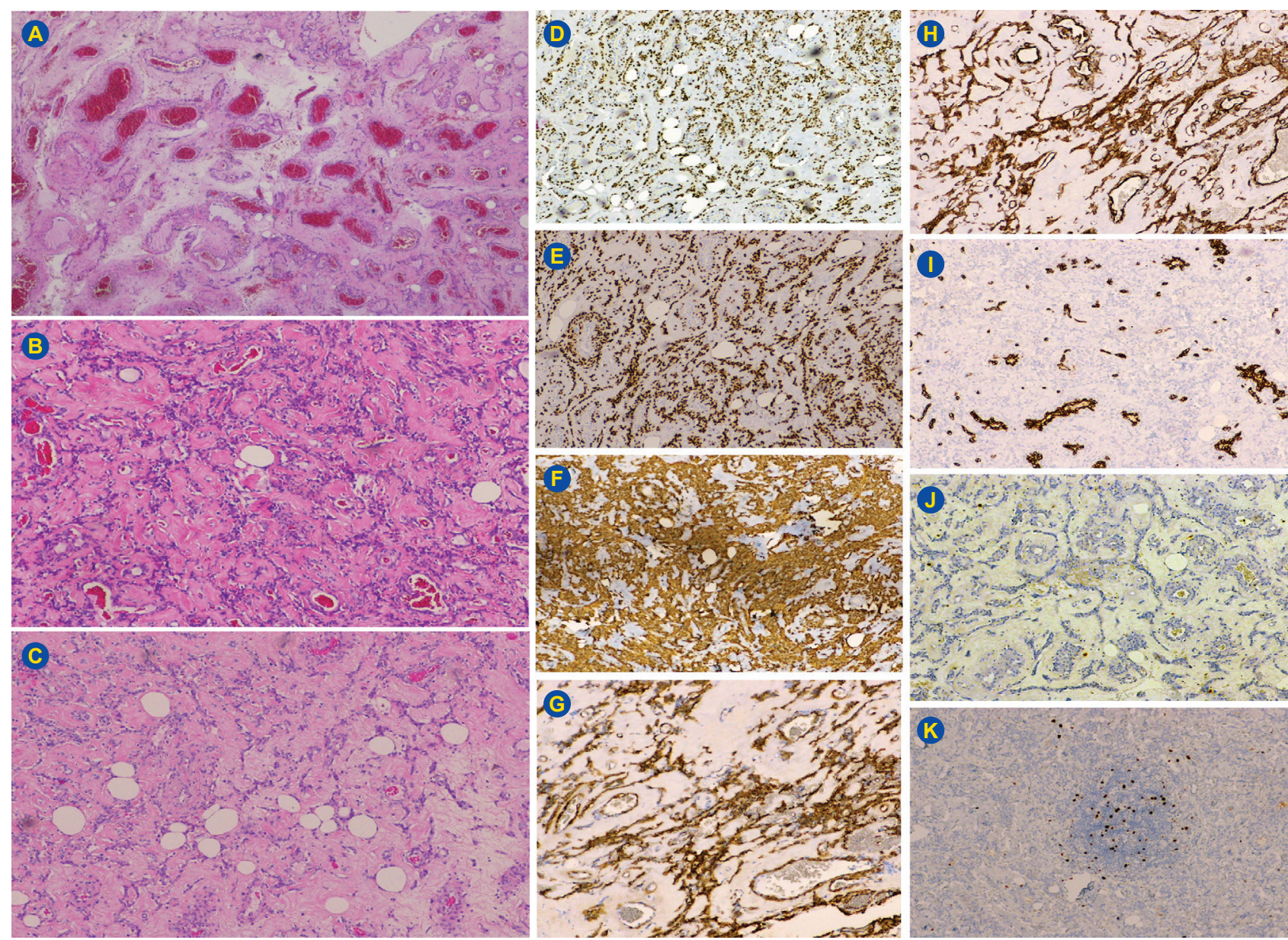

Figura 5 - Aspeto histopatológico e caraterização imuno-histoquímica da lesão: A: vasos abundantes de parede espessada; B: fascículos de células fusiformes envolvidos por feixes de colagénio; C: adipócitos no seio da lesão; D: positividade para receptores de estrogénio; E: positividade para receptores de progesterona; F: positividade para desmina; G: positividade para actina de músculo liso; H: positividade para caldesmon; I: negatividade para CD34; J: negatividade para S100; K: Ki-67 de 2\% - 3\%

acordo com os casos relatados, esta entidade aparenta ter um comportamento benigno, com baixas taxas de recidiva após excisão local completa, e com um bom prognóstico.

Este tumor é de relevância para a ginecologia, pois o local do seu aparecimento na mulher tem sido, maioritariamente, a nível da região vulvo-vaginal, mimetizando assim outras entidades ginecológicas frequentes, como é o exemplo dos quistos da glândula de Bartholin. A literatura apenas descreve um caso de localização pélvica retroperitoneal semelhante ao aqui relatado e, em ambas as situações, o AC apresentou um crescimento a nível da cavidade pélvica à direita.

Muito embora tivesse havido dúvidas quanto à origem do tumor, a sua localização bem como as caraterísticas imagiológicas descritas foram sugestivas de patologia da região anexial, pelo que foi solicitado apenas o marcador tumoral CA 125. Pela sua forma alongada a hipótese de se tratar de patologia da trompa foi colocada pela ecografia. Salientamos que esta formação pode ter apresentado um crescimento lento e daí a informação prévia da doente relativamente à presença já antiga de um quisto do anexo direito que, posteriormente, no decurso da cirurgia, não foi confirmado. Poderia tratar-se ab initio desta formação ainda com menores dimensões.

Apesar da raridade, a possibilidade da existência de um AC poderá ser considerada em situações de presença de formações nodulares ou alongadas, de caraterísticas imagiológicas inespecíficas que não se enquadrem num diagnóstico ginecológico exato, mas que se desenvolvam em localizações frequentes deste tipo de patologia. A conduta terapêutica, através da exérese, bem como a vigilância posterior, acaba por ser semelhante à oferecida para as lesões ginecológicas benignas típicas.

\section{CONFIDENCIALIDADE DOS DADOS}

Foi devidamente obtido o consentimento informado do doente.

\section{CONFLITOS DE INTERESSE}

Os autores declaram não terem qualquer conflito de interesse relativamente ao presente artigo.

\section{FONTES DE FINANCIAMENTO}

Não existiram subsídios ou bolsas que tenham contribuído para a realização do trabalho. 
1. Micheletti A, Lemo

1. Micheletti A, Lemos da Silva A, Nascimento A, Da Silva C, Murta E, Sheila A. Cellular angiofibroma of the vulva: case report with clinicopathological and immunohistochemistry study. Sao Paulo Med J. 2005;123:250-2.

2. Arora K. Soft tissue tumors-fibroblastic/myofibroblastic tumors: fellular angiofibroma. PatholoyOutlines.com. [consultado 2016 jul 11]. Disponível em: http://www.pathologyoutlines.com/topic/ softtissuecellularangiofibroma.html.

3. Mandato V, Santagni S, Cavazza A, Aguzzoli L, Abrate M, La Sala G. Cellular angiofibroma in women: a review of the literature. Diagn Pathol. 2015;10:114.
4. Nucci MR, Granter SR, Fletcher CD. Cellular angiofibroma: a benign neoplasm distinct from angiomyofibroblastoma and spindle cell lipoma. Am J Surg Pathol.1997;21:636-44.

5. Garijo MF, Val-Bernal JG. Extravulvar subcutaneous cellular angiofibroma. J Cutan Pathol. 1998;25:327-32.

6. Iwasa Y, Fletcher CD. Cellular angiofibroma: clinicopathologic and immunohistochemical analysis of 51 cases. Am J Surg Pathol. 2004;28:1426-35

7. Priyadarshi V, Sehgal N, Gupta SK, Kumar V, Singh M. Cellular angiofibroma: two case reports of a rare vulvar tumor. J Obstet Gynecol India. 2014;64:65-7.

\section{Infectious Mononucleosis and Cholestatic Hepatitis: A}

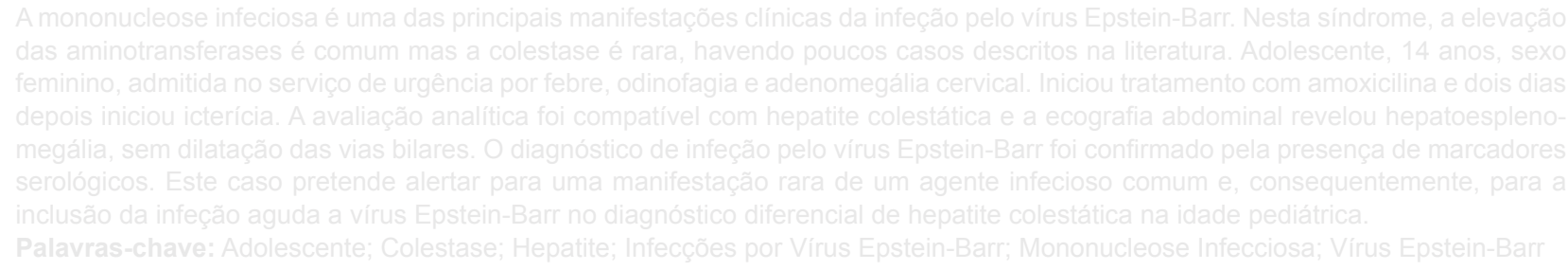

ABSTRACT

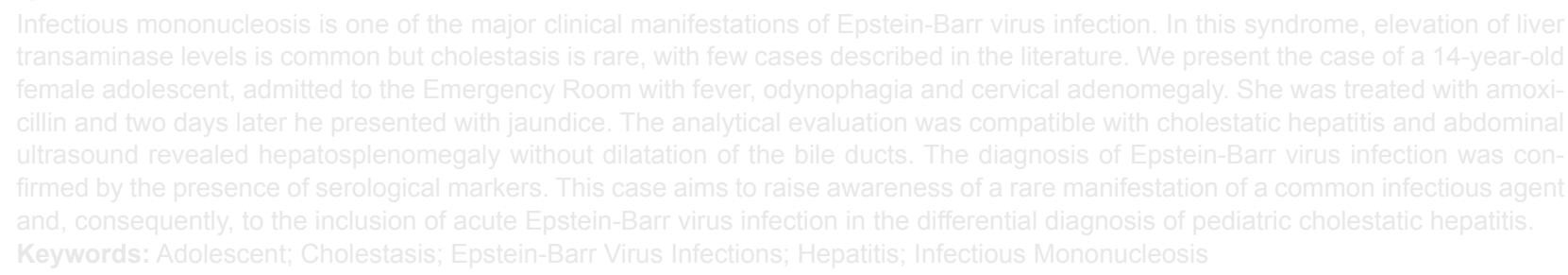

